\title{
A NOVEL STRUCTURE MODEL OF SOCIETIES
}

\author{
H.H. KLEIZEN \\ IDEGO, Delft University of Technology, the Netherlands.
}

\begin{abstract}
Sustainable development is an ongoing process which benefits from diversity in societies. In this paper, a novel structure model is presented allowing discussion of differences and similarities between societies differing in size and intentions such as cities, companies, and countries. The model uses a logarithmic distribution to classify a society into subsocieties. It then looks at the internal structure of societies in terms of these subsocieties and focuses on the largest subsocieties, in particular the three most densely populated ones. The model is applied to the world society and countries, the evolution of the European Union and discusses the effect of population size in societies with large differences in population but with the same internal structure: the world and the Dutch province South Holland. It is believed that this novel model contributes to the transparency of all kinds of societies and that they learn from each other thereby accelerating regional sustainable development for the overall benefit of the global community.

Keywords: cities, companies, countries, parliaments, population, provinces, society, structure model, sustainable development, world.
\end{abstract}

\section{INTRODUCTION}

Sustainable development has to do with global limitations and regional solutions. In that spirit a series of papers have been published recently by Kleizen [1-4] and a cornerstone of these publications is the structure of societies in terms of smaller societies down to the level of single women or men.

In this paper, a mathematical outline is given on how to describe a society in terms of its subsocieties in a practical manner. A novel 5-parameter model is presented and it is believed that studies of how different societies behave is best done when these societies have the same structural parameters, rather than lying in different parts of the world favoring financial support.

This model allows comparison of different societies. The difference may be in terms of value of parameters or in type. An international company may be compared with a small country and a parliament with a small or medium-sized enterprise.

Some examples are given about how this theory helps to identify societies purely by their internal structure and it is hoped that the societies learn from each other and together promote global sustainable development.

\section{TOO MANY DISTRIBUTIONS}

Societies have a structure, meaning simply that they are the sum of subsocieties. The smallest society is that of one human being and the largest society is the world population. The number of different distributions for a given society's population is huge and strongly dependent on the size of the population. With a population of about 135 , the number of distributions is already equal to the number of people living on the Earth at present.

In Table 1, the number of subsociety distributions for a society is presented up to a population of 22 people. The distributions are arranged according to the smallest subsociety present and the method of presentation is that of the automaton advocated by Wolfram [5].

There are already 1,002 different societies possible for a society of 32 people. The maximum number (792) is generated by distributions containing single persons. The minimum of one distribution 
Table 1: Number of different distributions of a society with $N$ members arranged according to the smallest subsociety present.

\begin{tabular}{|c|c|c|c|c|c|c|c|c|c|c|c|c|c|c|}
\hline$\Sigma$ & $N$ & 0 & 1 & 2 & 3 & 4 & 5 & 6 & 7 & 8 & 9 & 10 & 11 & $\Sigma$ \\
\hline 1 & 1 & 1 & & & & & & & & & & & & 1 \\
\hline 2 & 2 & 1 & 1 & & & & & & & & & & & 2 \\
\hline 3 & 3 & 1 & 2 & & & & & & & & & & & 3 \\
\hline 5 & 4 & 1 & 3 & 1 & & & & & & & & & & 5 \\
\hline 7 & 5 & 1 & 5 & 1 & & & & & & & & & & 7 \\
\hline 11 & 6 & 1 & 7 & 2 & 1 & & & & & & & & & 11 \\
\hline 15 & 7 & 1 & 11 & 2 & 1 & & & & & & & & & 15 \\
\hline 22 & 8 & 1 & 15 & 4 & 1 & 1 & & & & & & & & 22 \\
\hline 30 & 9 & 1 & 22 & 4 & 2 & 1 & & & & & & & & 30 \\
\hline 42 & 10 & 1 & 30 & 7 & 2 & 1 & 1 & & & & & & & 42 \\
\hline 56 & 11 & 1 & 42 & 8 & 3 & 1 & 1 & & & & & & & 56 \\
\hline 77 & 12 & 1 & 56 & 12 & 4 & 2 & 1 & 1 & & & & & & 77 \\
\hline 101 & 13 & 1 & 77 & 14 & 5 & 2 & 1 & 1 & & & & & & 101 \\
\hline 135 & 14 & 1 & 101 & 21 & 6 & 3 & 1 & 1 & 1 & & & & & 135 \\
\hline 176 & 15 & 1 & 135 & 24 & 9 & 3 & 2 & 1 & 1 & & & & & 176 \\
\hline 231 & 16 & 1 & 176 & 34 & 10 & 5 & 2 & 1 & 1 & 1 & & & & 231 \\
\hline 297 & 17 & 1 & 231 & 41 & 13 & 5 & 3 & 1 & 1 & 1 & & & & 297 \\
\hline 385 & 18 & 1 & 297 & 55 & 17 & 7 & 3 & 2 & 1 & 1 & 1 & & & 385 \\
\hline 490 & 19 & 1 & 385 & 66 & 21 & 8 & 4 & 2 & 1 & 1 & 1 & & & 490 \\
\hline 627 & 20 & 1 & 490 & 88 & 25 & 11 & 5 & 3 & 1 & 1 & 1 & 1 & & 627 \\
\hline 792 & 21 & 1 & 627 & 105 & 33 & 12 & 6 & 3 & 2 & 1 & 1 & 1 & & 792 \\
\hline 1,002 & 22 & 1 & 792 & 137 & 39 & 16 & 7 & 4 & 2 & 1 & 1 & 1 & 1 & 1,002 \\
\hline
\end{tabular}

is found for either no subsocieties (one subsociety coinciding with the society) and at the other end of the scale two subsocieties of equal size if $N$ is even (both 11 for $N=22$ ).

Another way to present the distributions is top-down, which is shown in Table 2. The automaton picture of Table 2 is quite different from that of Table 1 . The number of distributions containing large subsocieties is indifferent to the population size. The maximum number of distributions is found for small subsocieties ( $N=22$ : subsocieties containing 6 people). But it is a weak maximum ( $N=22: 136$ distributions). The number of distributions is 1 in the three cases: (i) subsociety equals the society (both $N$ ); (ii) two subsocieties, one with $N-1$ members; and (iii) $N$ subsocieties (all subsocieties consisting of single persons).

Top-down and bottom-up representations give the same information regarding the number of distributions but highlight different aspects. For a chemist looking for dioxin molecules and for a physicist trying to understand entropy, the bottom-up approach is followed. In this paper, the focus is top-down starting with the world population and the major countries, and not so much a single person on an island. The major problem is that there are so many distributions that a full comparison is impossible. A simplified scheme is needed, leaving enough room for comparison of societies.

\section{STRUCTURE MODEL}

The first step in the structure model is to describe the population with a logarithmic distribution. The class width selected is 2 , so that in each class the population varies around the class average value of 


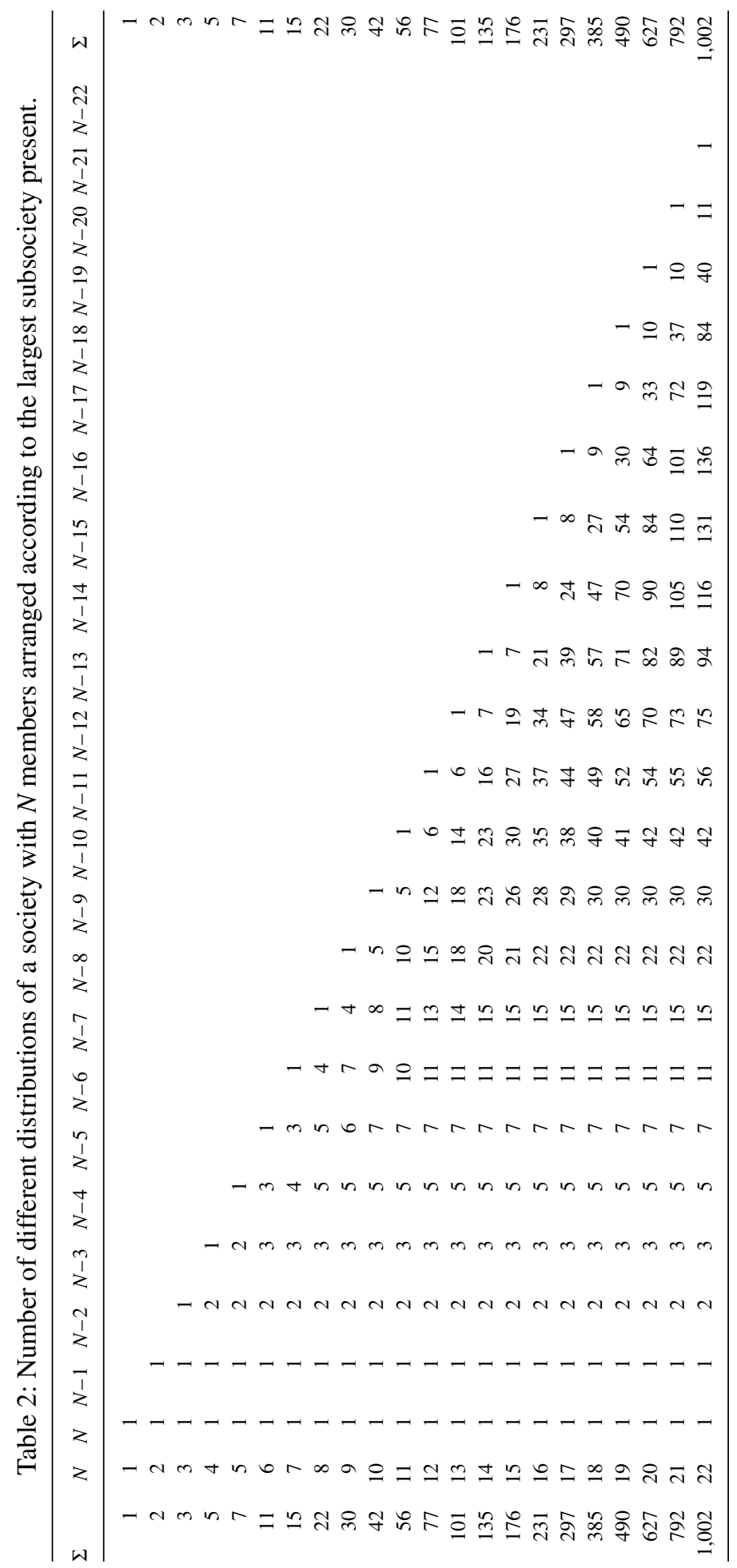


Table 3: The first eight classes and their number of distributions $A_{n}$.

\begin{tabular}{lcrcc}
\hline$N$ & $N_{\text {min }}$ & $N_{\text {ave }}$ & $N_{\max }$ & $A_{n}$ \\
\hline 0 & 1 & 1 & 1 & 1 \\
1 & 1 & 2 & 2 & 2 \\
2 & 3 & 4 & 5 & 15 \\
3 & 6 & 8 & 11 & 176 \\
4 & 12 & 16 & 22 & 4,313 \\
5 & 23 & 32 & 45 & 536,127 \\
6 & 46 & 64 & 90 & $4.65 \mathrm{E}+08$ \\
7 & 91 & 128 & 181 & $8.48 \mathrm{E}+12$ \\
\hline
\end{tabular}

$N$ from $N / \sqrt{2}$ to $N / \sqrt{2}$. The average is written as $2^{n}$ and it is proposed that the exponent $n$ is an integer or zero. In Table 3 , the population range and the number of distributions $A_{n}$ are given.

Subsocieties are described in the same way, so in general $(n>2)$ the sum of the population in the subsocieties is not equal to that of the society,

$$
2^{n} \neq c_{0} \cdot 2^{n}+c_{1} \cdot 2^{n-1}+\mathrm{L}+c_{n-1} \cdot 2+c_{n} .
$$

Restoration of equality is only possible by ignoring and changing part of the right-hand side of the inequality. In the top-down approach, the smaller subsocieties are sacrificed. The equation for the structure model starts with the largest subsocieties,

$$
2^{n}=b_{0} \cdot 2^{n-m}+b_{1} \cdot 2^{n-m-1}+b_{2} \cdot 2^{n-m-2}+b_{3} \cdot 2^{n-m-3}+\mathrm{L} .
$$

In eqn (2) the second model parameter $m$ is introduced, which is equal to the difference between the exponent of the society and those of its largest subsocieties. The indices $b_{i}$ will differ from the coefficients $c_{i}$ because the population society and subsociety are independently modeled in terms of powers of 2. In general, the index and coefficient of the smallest subsociety will be different. The number of indices, $b_{i}$, that are taken into account is a free choice. Table 4 illustrates the transition from coefficients to indices (up to four) for small societies $(N \leq 6)$. Such a modeled distribution will be called a configuration.

The description in terms of three indices starts to differ at $N=6$, the first member of the class $n=3$. In general, with $x$ indices the description will differ beginning with the first member of the class $n=x$. Thus the description with two, three, and four indices becomes manifest, respectively, at $N=3, N=6$, and $N=12$ (see also Table 3).

With an increasing number of indices, the number of allowed configurations increases sharply as can be concluded from Table 5 .

The aim is to assess the largest subsocieties as correctly as possible without generating too many configurations as they are needed for the correct description of smaller subsocieties. Considering these aspects the choice is made for three indices in the literature by Kleizen [1-4] called $h, k$, and $l$, transforming eqn (2) to,

$$
2^{n}=h \cdot 2^{n-m}+k \cdot 2^{n-m-1}+l \cdot 2^{n-m-2},
$$


Table 4: Modeling subsociety distributions of societies up to six persons with one, up to four indices.

\begin{tabular}{|c|c|c|c|c|c|c|c|c|c|c|c|c|c|c|c|c|c|c|c|c|c|c|}
\hline$N$ & & & stril & but & & & $n$ & $m$ & $c_{0}$ & $c_{1}$ & $c_{2}$ & $c_{3}$ & $b_{0}$ & $b_{0}$ & $b_{1}$ & $b_{0}$ & $b_{1}$ & $b_{2}$ & $b_{0}$ & $b_{1}$ & $b_{2}$ & $b_{3}$ \\
\hline 1 & 1 & & & & & & 0 & 0 & 1 & 0 & 0 & 0 & 1 & 1 & 0 & 1 & 0 & 0 & 1 & 0 & 0 & 0 \\
\hline 2 & 2 & & & & & & 1 & 0 & 1 & 0 & 0 & 0 & 1 & 1 & 0 & 1 & 0 & 0 & 1 & 0 & 0 & 0 \\
\hline 2 & 1 & 1 & & & & & 1 & 1 & 0 & 2 & 0 & 0 & 2 & 2 & 0 & 2 & 0 & 0 & 2 & 0 & 0 & 0 \\
\hline 3 & 3 & & & & & & 2 & 0 & 1 & 0 & 0 & 0 & 1 & 1 & 0 & 1 & 0 & 0 & 1 & 0 & 0 & 0 \\
\hline 3 & 2 & 1 & & & & & 2 & 1 & 0 & 1 & 1 & 0 & 2 & 1 & 2 & 1 & 2 & 0 & 1 & 2 & 0 & 0 \\
\hline 3 & 1 & 1 & 1 & & & & 2 & 2 & 0 & 0 & 3 & 0 & 4 & 4 & 0 & 4 & 0 & 0 & 4 & 0 & 0 & 0 \\
\hline 4 & 4 & & & & & & 2 & 0 & 1 & 0 & 0 & 0 & 1 & 1 & 0 & 1 & 0 & 0 & 1 & 0 & 0 & 0 \\
\hline 4 & 3 & 1 & & & & & 2 & 0 & 1 & 0 & 1 & 0 & 1 & 1 & 0 & 1 & 0 & 0 & 1 & 0 & 0 & 0 \\
\hline 4 & 2 & 2 & & & & & 2 & 1 & 0 & 2 & 0 & 0 & 2 & 2 & 0 & 2 & 0 & 0 & 2 & 0 & 0 & 0 \\
\hline 4 & 2 & 1 & 1 & & & & 2 & 1 & 0 & 1 & 2 & 0 & 2 & 1 & 2 & 1 & 2 & 0 & 1 & 2 & 0 & 0 \\
\hline 4 & 1 & 1 & 1 & 1 & & & 2 & 2 & 0 & 0 & 4 & 0 & 4 & 4 & 0 & 4 & 0 & 0 & 4 & 0 & 0 & 0 \\
\hline 5 & 5 & & & & & & 2 & 0 & 1 & 0 & 0 & 0 & 1 & 1 & 0 & 1 & 0 & 0 & 1 & 0 & 0 & 0 \\
\hline 5 & 4 & 1 & & & & & 2 & 0 & 1 & 0 & 1 & 0 & 1 & 1 & 0 & 1 & 0 & 0 & 1 & 0 & 0 & 0 \\
\hline 5 & 3 & 2 & & & & & 2 & 0 & 1 & 1 & 0 & 0 & 1 & 1 & 0 & 1 & 0 & 0 & 1 & 0 & 0 & 0 \\
\hline 5 & 3 & 1 & 1 & & & & 2 & 0 & 1 & 0 & 2 & 0 & 1 & 1 & 0 & 1 & 0 & 0 & 1 & 0 & 0 & 0 \\
\hline 5 & 2 & 2 & 1 & & & & 2 & 1 & 0 & 2 & 1 & 0 & 2 & 2 & 0 & 2 & 0 & 0 & 2 & 0 & 0 & 0 \\
\hline 5 & 2 & 1 & 1 & 1 & & & 2 & 1 & 0 & 1 & 3 & 0 & 2 & 1 & 2 & 1 & 2 & 0 & 1 & 2 & 0 & 0 \\
\hline 5 & 1 & 1 & 1 & 1 & 1 & & 2 & 2 & 0 & 0 & 5 & 0 & 4 & 4 & 0 & 4 & 0 & 0 & 4 & 0 & 0 & 0 \\
\hline 6 & 6 & & & & & & 3 & 0 & 1 & 0 & 0 & 0 & 1 & 1 & 0 & 1 & 0 & 0 & 1 & 0 & 0 & 0 \\
\hline 6 & 5 & 1 & & & & & 3 & 1 & 0 & 1 & 0 & 1 & 2 & 1 & 2 & 1 & 0 & 4 & 1 & 0 & 4 & 0 \\
\hline 6 & 4 & 2 & & & & & 3 & 1 & 0 & 1 & 1 & 0 & 2 & 1 & 2 & 1 & 1 & 2 & 1 & 1 & 2 & 0 \\
\hline 6 & 4 & 1 & 1 & & & & 3 & 1 & 0 & 1 & 0 & 2 & 2 & 1 & 2 & 1 & 0 & 4 & 1 & 0 & 4 & 0 \\
\hline 6 & 3 & 3 & & & & & 3 & 1 & 0 & 2 & 0 & 0 & 2 & 2 & 0 & 2 & 0 & 0 & 2 & 0 & 0 & 0 \\
\hline 6 & 3 & 2 & 1 & & & & 3 & 1 & 0 & 1 & 1 & 1 & 2 & 1 & 2 & 1 & 1 & 2 & 1 & 1 & 2 & 0 \\
\hline 6 & 3 & 1 & 1 & 1 & & & 3 & 1 & 0 & 1 & 0 & 1 & 2 & 1 & 2 & 1 & 0 & 4 & 1 & 0 & 4 & 0 \\
\hline 6 & 2 & 2 & 2 & & & & 3 & 2 & 0 & 0 & 3 & 0 & 4 & 3 & 2 & 3 & 2 & 0 & 3 & 2 & 0 & 0 \\
\hline 6 & 2 & 2 & 1 & 1 & & & 3 & 2 & 0 & 0 & 2 & 2 & 4 & 2 & 4 & 2 & 4 & 0 & 2 & 4 & 0 & 0 \\
\hline 6 & 2 & 1 & 1 & 1 & 1 & & 3 & 2 & 0 & 0 & 1 & 4 & 4 & 1 & 6 & 1 & 6 & 0 & 1 & 6 & 0 & 0 \\
\hline 6 & 1 & 1 & 1 & 1 & 1 & 1 & 3 & 3 & 0 & 0 & 0 & 6 & 8 & 8 & 0 & 8 & 0 & 0 & 8 & 0 & 0 & 0 \\
\hline
\end{tabular}

with $h$ at least equal to 1 since there has to be at least one largest subsociety. The equation contains five parameters linked by the equation and by the condition of either being $0(n, m, k, l)$ or natural numbers (all five). In Table 6 the allowed $h k l$-configurations are presented up to $m=3$.

The total number of $h k l$-configurations listed in Table 6 is only 85 and including $m=4$ raises it to 341. So with these low $m$-values it makes sense to study and compare societies by their $h k l$-configuration.

\section{APPLICATIONS}

In this section, various applications are summarized. Some of these findings have been already published by Kleizen [1-4] and will be reviewed and others are simply new. 
Table 5: Number of configurations as a function of $m$ for different numbers of indices.

\begin{tabular}{lcccc}
\hline & 1 & 2 & 3 & 4 \\
$m$ & $1^{m}$ & $2^{m}$ & $4^{m}$ & $\Sigma\left(2^{m+1}-1\right)^{2}$ \\
\hline 0 & 1 & 1 & 1 & 1 \\
1 & 1 & 2 & 4 & 10 \\
2 & 1 & 4 & 16 & 84 \\
3 & 1 & 8 & 64 & 680 \\
4 & 1 & 16 & 256 & 5,456 \\
\hline
\end{tabular}

\subsection{Nesting}

The first question is how large $m$ can be, as its maximal value determines how many configurations should be taken into account: $85\left(m_{\max }=3\right), 341\left(m_{\max }=4\right)$, or substantially more $\left(1,365\right.$ if $\left.m_{\max }=5\right)$. Nesting is the number of scales that exists between the world population and a single person. The gap is filled by subsocieties such as households, streets, neighborhoods, cities, provinces, countries, and no doubt others. Clearly with an $m$-value independent of society scale, nesting is related to the maximal value of $m$.

The quest towards the maximal value of $m$ is an ongoing story. There are simply too many societies and their structure is not always published or explicitly felt. Table 7 gives the range of $m$-values found to date and examples of societies with these $m$-values.

The current impression is that $m_{\max }=4$ is a maximum but that it seldom occurs. The distribution of $m$-values peaks presumably at $m=3$. So in practice, the 85 configurations will be sufficient. The CIA World Factbook [6] estimates the world population in July 2005 at 6.45 billion. That $N$-value corresponds to $n=33$. If $m=3$ independent of scale, then there is room for 13 scales starting at $n=33$ and ending at $n=0$. Thirteen scales allow a half billion $(12 !=4.8 \mathrm{E} 8)$ nesting studies.

\subsection{World population and countries}

The CIA World Factbook [6] identifies 236 permanently inhabited areas in the world in July 2005. In Fig. 1, the 236 countries are classified according to their $n$-value. China and India with $n=30$ are the two largest subsocieties of the world population with $n=33$, so that $m=3$. Countries with $n=29$ are lacking and only USA and Indonesia have $n=28$ populations. The $h \mathrm{kl}$-configuration of the world society is thus 2024 . (The convention is to underline the $k$-index in case of ambiguity.)

China and India thus dominate the world scene. It is of some interest to compare their internal structure. China has 32 administrative divisions and from internet population data [7] it has $m=3$ and $h k l$ indices 1910 (see also Table 6). India has 35 administrative divisions and also $m=3$ and a slightly different $h k l$-configuration: 288 . Thus, both China and India have $10 h k$-subsocieties. And from Table 8 it can be seen that the total population as well as the total area of these 10 administrative subdivisions is almost the same. This notion can be a starting point to analyze further the differences and similarities between these administrative divisions.

\subsection{European Union (EU) evolution}

In the 50 years of its existence, the EU increased its member states from 6 to 27 . The chronology is shown in Table 9. In the beginning, it started with one $h$-subsociety, West Germany; two $k$-subsocieties, 


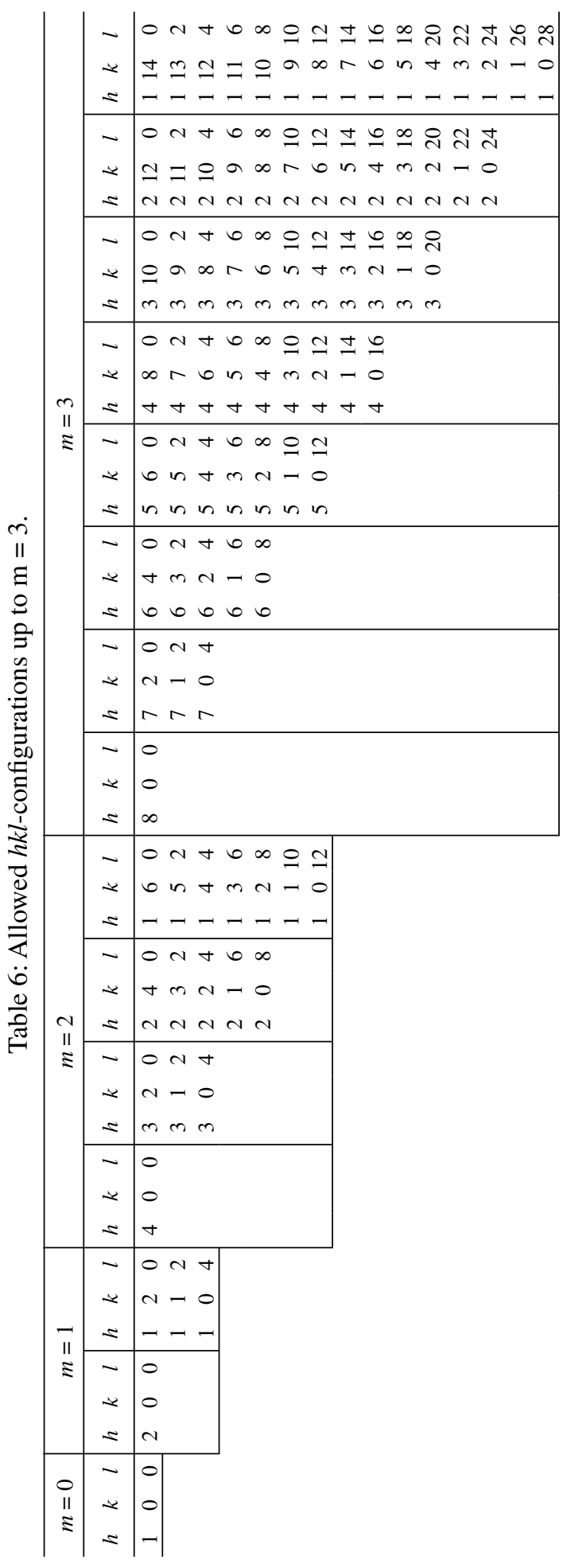


Table 7: Societies with different $m$-values [1, 3].

\begin{tabular}{lcclccc}
\hline Society & Population & $n$ & Largest subsociety & Population & $n-m$ & $m$ \\
\hline Nevada (US) & $2.2 \mathrm{E}+06$ & 21 & Clark County & $1.6 \mathrm{E}+06$ & 21 & 0 \\
Australia and Oceania & $3.3 \mathrm{E}+07$ & 25 & Australia & $2.0 \mathrm{E}+07$ & 24 & 1 \\
Spain & $4.3 \mathrm{E}+07$ & 25 & Andalucia Province & $7.6 \mathrm{E}+06$ & 23 & 2 \\
EU-25 & $4.6 \mathrm{E}+08$ & 29 & Germany & $8.2 \mathrm{E}+07$ & 26 & 3 \\
Gelderland (Netherlands) & $2.0 \mathrm{E}+06$ & 21 & Nijmegen City & $1.6 \mathrm{E}+05$ & 17 & 4 \\
\hline
\end{tabular}

France and Italy; and three small subsocieties, collectively named Benelux. It had a population comparable with Pakistan at present and the parameter set $n=27, m=2$, and $h k l$-indices 120 . With a growing population and number of member states, $n$ increased by 1 and was dominated by the four large countries: West Germany, France, Italy, and the UK. The increase of $m$ after the wave of 10 countries in 2004 changed the picture, and smaller subsocieties entered the configuration 4212 . The increase to 27 countries has had no effect as the EU is still trying to cope with the 2004 change in its political playground.

With $n=29$ the EU comes third directly behind China and India. It has the same value as these two countries but has only six $h k$-countries, which are listed in Table 10 . The area of the EU $h k$-countries hardly differs from that of China and India (see Table 8 ). The difference is the number of people. The $h k$-countries accommodate half the number of people in the corresponding subsocieties of China and India.

The question is how well the EU is equipped to strengthen the relationships between its $h k$-countries considering their cultural differences as suggested by Kleizen [1-3].

\subsection{Scaling}

Scaling is defined, here, as two societies with the same structural parameters ( $m$ and indices $h k l$ ) but different only in $n$. A search was launched to find a society with the same structural parameters as the world society. So far one society was found [1, 4]. The Dutch province South Holland has an $n$-value of 22 hosting two major cities: Rotterdam and the Hague. So a comparison could be made between the world society with the countries China and India and the Dutch province South Holland with the cities Rotterdam and the Hague.

In Table 11 the major properties of these two societies and their largest subsocieties are compared. The template behind Table 11 is extracted from the CIA World Factbook [6], skipping three themes: economy, military, and transnational issues. The CIA World Factbook deals with the world and its countries. All data regarding the province South Holland and its largest cities stem from other sources $[1,4]$.

In the category 'geography' the cities relate to the province as the countries relate to the world. The exception is the carbon dioxide emission per capita. It has to increase in the countries and/or decrease in the cities. This trend is present and so the match is improving.

In the category 'people' a similar discrepancy can be noted. The median age in India and the Hague are in line with the world and province, but the median age in Rotterdam and China show opposite figures. Rotterdam must increase its median age beyond that of the province. And indeed it has problems in maintaining its young workforce, as the main port function requires more computers than hands. 


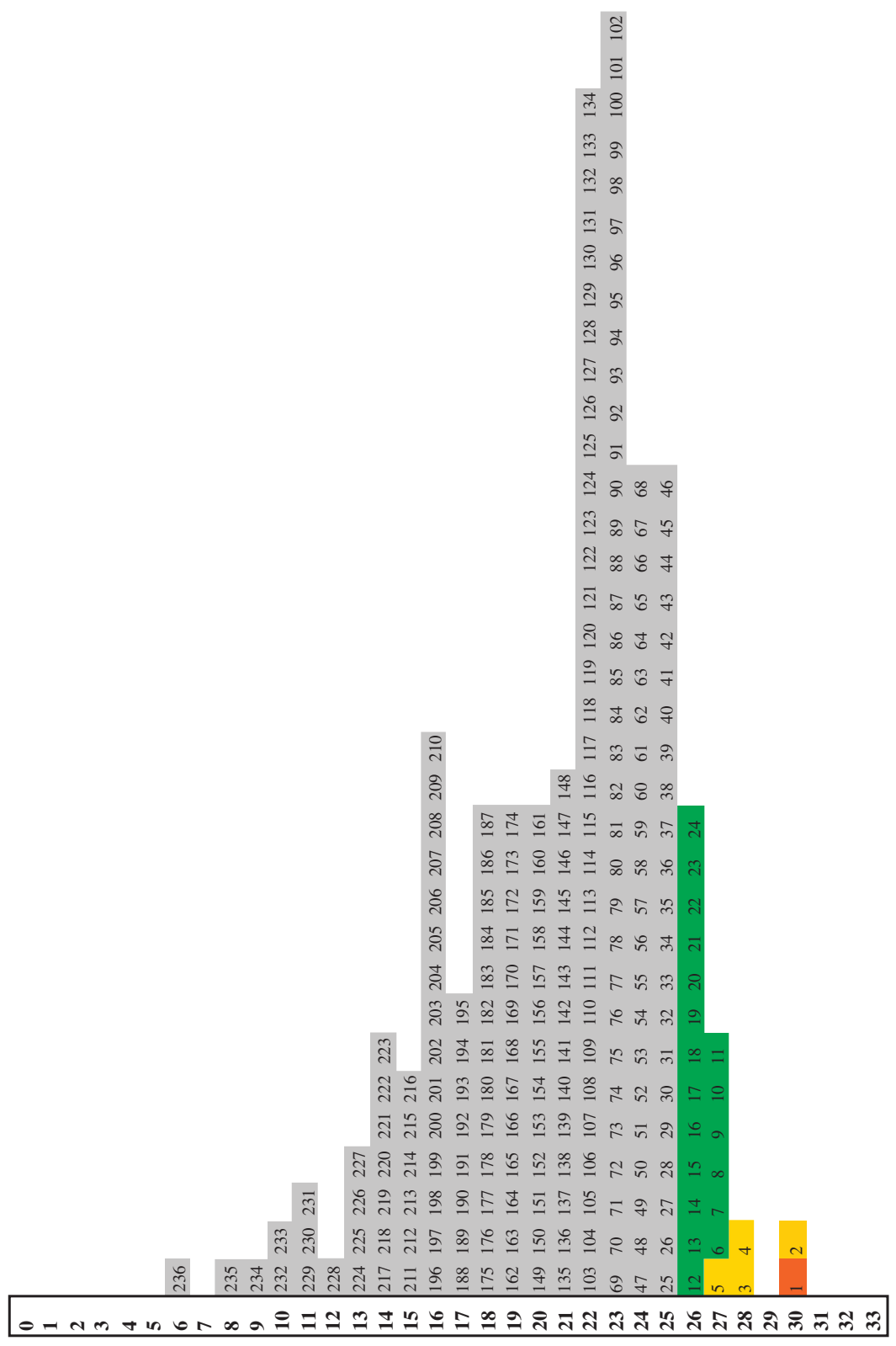

Figure 1: The world population in terms of the $n$-values of the 236 countries [1-4].

The Hague is a society without any structure in subsocieties. Another difference in the category 'government' is the lack of a world government. Both issues are debated. In the Hague, there have been plans and the United Nations is a candidate. The administrative subdivisions reveal all $m=3$ but the $h k l$-configuration of Rotterdam differs from that of China. In China, the $k$-subsocieties have the population majority while in Rotterdam the $h$-subsocieties rule. Rotterdam could improve the 


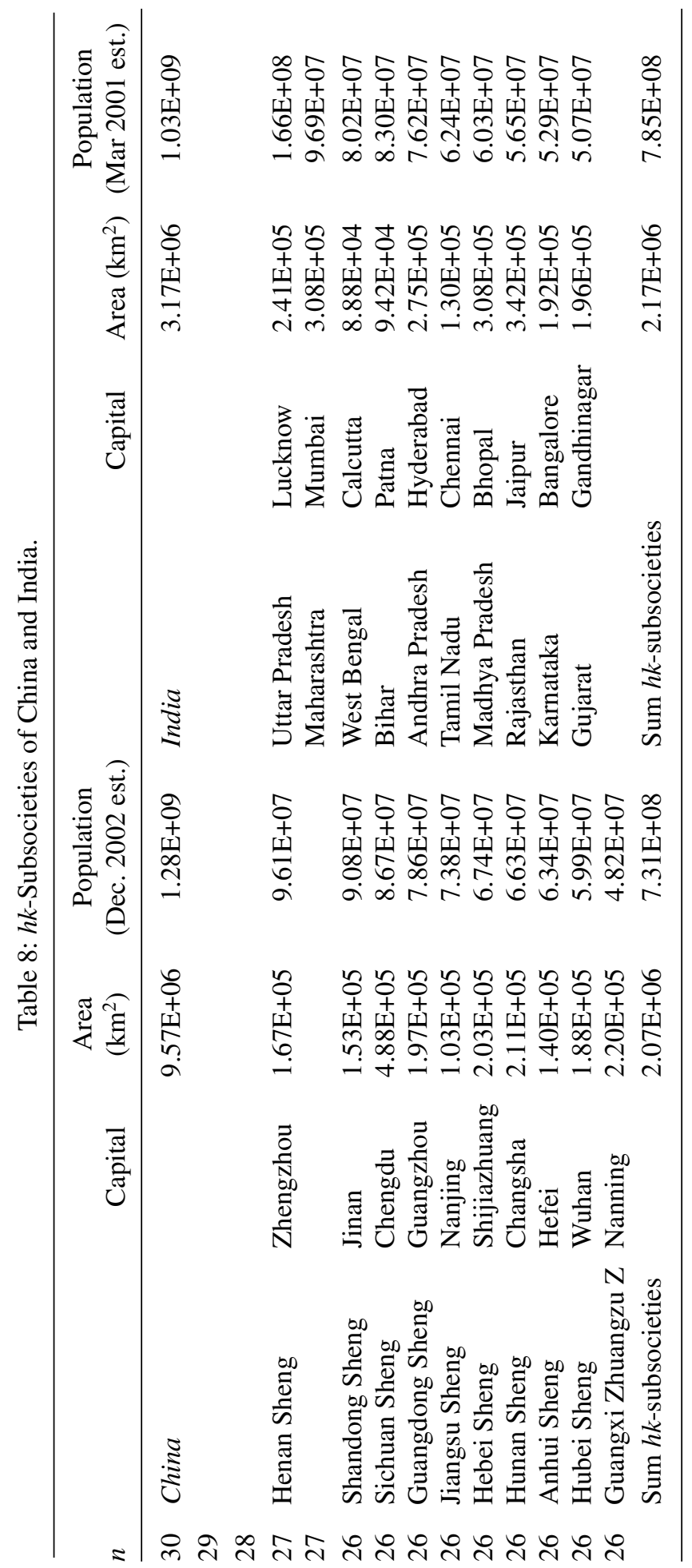


Table 9: Evolution of the EU [3].

\begin{tabular}{lcccccc}
\hline & & \multicolumn{5}{c}{ Model parameters } \\
\cline { 3 - 7 } EU & Population (est.) & $n$ & $m$ & $h$ & $k$ & $l$ \\
\hline 1952 & $1.60 \mathrm{E}+08$ & 27 & 1 & 1 & 2 & 0 \\
1973 & $2.58 \mathrm{E}+08$ & 28 & 2 & 4 & 0 & 0 \\
1985 & $3.26 \mathrm{E}+08$ & 28 & 2 & 4 & 0 & 0 \\
1995 & $3.74 \mathrm{E}+08$ & 28 & 2 & 4 & 0 & 0 \\
2004 & $4.57 \mathrm{E}+08$ & 29 & 3 & 4 & 2 & 12 \\
2007 & $4.87 \mathrm{E}+08$ & 29 & 3 & 4 & 2 & 12 \\
\hline
\end{tabular}

Table 10: The $h k$-countries of the EU.

\begin{tabular}{lllcc}
\hline$n$ & & Capital & Area $\left(\mathrm{km}^{2}\right)$ & $\begin{array}{c}\text { Population } \\
\text { (July 2007 est.) }\end{array}$ \\
\hline 29 & EU-27 & & $4.33 \mathrm{E}+06$ & $4.90 \mathrm{E}+08$ \\
28 & & & \\
27 & & & \\
26 & Germany & Berlin & $3.57 \mathrm{E}+05$ & $8.24 \mathrm{E}+07$ \\
26 & France & Paris & $5.47 \mathrm{E}+05$ & $6.37 \mathrm{E}+07$ \\
26 & UK & London & $2.45 \mathrm{E}+05$ & $6.08 \mathrm{E}+07$ \\
26 & Italy & Rome & $3.01 \mathrm{E}+05$ & $5.81 \mathrm{E}+07$ \\
25 & Spain & Madrid & $5.05 \mathrm{E}+05$ & $4.04 \mathrm{E}+07$ \\
25 & Poland & Warsaw & $3.13 \mathrm{E}+05$ & $3.85 \mathrm{E}+07$ \\
& Sum $h k$-subsocieties & & $2.27 \mathrm{E}+06$ & $3.44 \mathrm{E}+08$ \\
\hline
\end{tabular}

match by breaking down its $h$-subsocieties or China could combine $k$-subsocieties. But the trend in China is opposite: major cities are directly placed under the central government thereby creating more subsocieties rather than forming less.

Parliament seats are also societies and the political parties that occupy these seats are subsocieties. Again there is little agreement apart from that in Rotterdam and China the $h$-political parties rule. And as far as independence is concerned, China and Rotterdam are older than their counterparts. But what should be taken for the world's independence?

In the sector 'transportation', the Hague and India are in line, in terms of meters/capita highways but data for Rotterdam are lacking. The difference in numbers of cars/capita is negligible in both and in that sense fit in the comparison. The same goes for the number of airports/capita.

It can be concluded by and large that China and Rotterdam are more a pair and that the Hague and India are alike. So the impression surfaces that two large subsocieties with the same $n$-value embedded in the same $h k l$-configuration (2024) relate to each other in a similar way independent of the $n$-value of the society (world: $n=33$; South Holland: $n=22$ ).

Another conclusion is that on the country scale much more is known than on the city level. It would help if the cities adopted the CIA template of categories and supplied the relevant data. 
Table 11: Scaling societies: the world and South Holland [1, 4].

\begin{tabular}{|c|c|c|c|c|c|c|}
\hline & World & China & India & South Holland & Rotterdam & The Hague \\
\hline \multicolumn{7}{|l|}{ Geography } \\
\hline \multicolumn{7}{|l|}{ Land area } \\
\hline $\mathrm{m}^{2}$ & $1.3 \mathrm{E}+14$ & $9.3 \mathrm{E}+12$ & $3.0 \mathrm{E}+12$ & $2.9 \mathrm{E}+09$ & $2.1 \mathrm{E}+08$ & $8.1 \mathrm{E}+07$ \\
\hline $\mathrm{m}^{2} /$ cap & 20,521 & 7,139 & 2,752 & 845 & 348 & 172 \\
\hline \multicolumn{7}{|l|}{ Carbon dioxide } \\
\hline $\mathrm{kg} /$ year & $2.4 \mathrm{E}+13$ & $3.5 \mathrm{E}+12$ & $1.2 \mathrm{E}+12$ & $4.2 \mathrm{E}+10$ & $2.4 \mathrm{E}+10$ & $1.6 \mathrm{E}+09$ \\
\hline kg/year/cap & 3,774 & 2,685 & 1,128 & 12,083 & 40,144 & 3,478 \\
\hline \multicolumn{7}{|l|}{ People } \\
\hline Population & $6.5 \mathrm{E}+09$ & $1.3 \mathrm{E}+09$ & $1.1 \mathrm{E}+09$ & $3.5 \mathrm{E}+06$ & $6.0 \mathrm{E}+05$ & 4.7E+05 \\
\hline$n$ & 33 & 30 & 30 & 22 & 19 & 19 \\
\hline Median age (year) & 27.6 & 32.3 & 24.7 & 36.9 & 35.2 & 35.6 \\
\hline \multicolumn{7}{|l|}{ Government } \\
\hline Administrative subdivisions & 236 & 32 & 35 & 86 & 14 & \\
\hline$m$ & 3 & 3 & 3 & 3 & 3 & \\
\hline$h \underline{k} l$ & $2 \underline{0} 24$ & 1910 & $2 \underline{8} 8$ & $2 \underline{0} 24$ & $7 \underline{2} 0$ & \\
\hline Parliament seats & & 2,979 & 545 & 83 & 45 & 45 \\
\hline$n$ & & 12 & 9 & 6 & 5 & 5 \\
\hline Political parties & & 1 & 40 & 10 & 8 & 12 \\
\hline$m$ & & 0 & 2 & 2 & 1 & 1 \\
\hline$h \underline{k} l$ & & $1 \underline{0} 0$ & $2 \underline{0} 8$ & $3 \underline{12}$ & $2 \underline{0} 0$ & $1 \underline{12}$ \\
\hline Independence (year) & & $221 \mathrm{BC}$ & 1949 & 1795 & 1340 & 1806 \\
\hline \multicolumn{7}{|l|}{ Transportation } \\
\hline \multicolumn{7}{|l|}{ Highways } \\
\hline $\mathrm{m}$ & $3.2 \mathrm{E}+10$ & $1.8 \mathrm{E}+09$ & $2.5 \mathrm{E}+09$ & $1.4 \mathrm{E}+07$ & & $1.2 \mathrm{E}+06$ \\
\hline $\mathrm{m} / \mathrm{cap}$ & 5.0 & 1.4 & 2.3 & 3.9 & & 2.6 \\
\hline Cars & $7.0 \mathrm{E}+07$ & $2.0 \mathrm{E}+07$ & $9.0 \mathrm{E}+06$ & $1.2 \mathrm{E}+06$ & $2.0 \mathrm{E}+05$ & $1.7 \mathrm{E}+05$ \\
\hline Car/cap & 0.01 & 0.02 & 0.01 & 0.35 & 0.33 & 0.35 \\
\hline Airports & 49,973 & 472 & 333 & 2 & 1 & 0 \\
\hline
\end{tabular}

\subsection{Companies}

Companies are societies of employees. In Table 12 some dated distributions of employees are given for two multinationals [8,9]. These two societies have the same $n$-value 17 , but differ in their internal structure. Philips has $m=2$ and the $h k l$-indices 320 and Shell has $m=1$ and the $h k l$-configuration 104. Philips employees together have five skills while Shell employees have only one skill.

Currently, Philips has sold its Semiconductor division thereby changing its structure in the direction of Shell which is perhaps moving towards Philips by increasing its Exploration activities.

The question being how many skills a multinational should have and how these divisions are further structured: all the same or product-driven. More research is necessary to include information not only on large enterprises but also on small or medium-sized enterprises and scaling. 
Table 12: Distribution of employees of Philips Group and Royal Dutch Shell.

\begin{tabular}{llrlr}
\hline$n$ & & Employees 2005 & Employees 2004 \\
\hline 17 & Philips Group & 159,226 & Royal Dutch Shell & 112,000 \\
16 & & & Oil products & 76,000 \\
15 & Lighting & 45,649 & & \\
& Semiconductors & 35,637 & & \\
& Medical systems & 30,978 & & 17,000 \\
14 & Other activities & 19,050 & Exploration and production & \\
& Consumer electronics & 15,537 & & 9,000 \\
13 & DAP & & Other segments and corporate & 8,000 \\
& & 8,203 & Chemistry & 2,000 \\
11 & Unallocated & 2,392 & Gas and electricity & \\
& Discontinued operations & 1,780 & & \\
\hline
\end{tabular}

\section{CONCLUSION}

The structure model is a new tool to describe and track down differences and similarities. No doubt it is an attractive tool for societies to learn from each other and it contributes to increased transparency of societies. Transparency, standardization of data to be collected, and data exchange are prerequisites for sustainable development. But as always, a lot of research is needed to establish its role in the toolkit.

One way to do that is to link it with culture. The first results are promising [1-3]. It is believed that it can also be of value in societies other than human societies, such as animal and insect societies. Currently, the research focus is directed to find links with the behavior of non-living matter and biomolecules.

The structure model with the three indices configuration is a valuable tool in the communication between human societies on the track of sustainable development.

\section{REFERENCES}

[1] Kleizen, H.H., Towards a Sustainable Technological World, VSSD: Delft, 2007.

[2] Kleizen, H.H., Towards a sustainable world. Proc. of the 1st Int. Conf. on the Management of Natural Resources Sustainable Development, The Ravage of the Planet, eds C.A. Brebbia, M.E. Conti \& E. Tiezzi, WIT Press: Southampton, pp. 45-54, 2006.

[3] Kleizen, H.H., A novel method to structure the world in population entities and application towards European countries and regions. 46th ERSA Conf., Volos, 2006.

[4] Kleizen, H.H., Structuring the world down to cities and sustainable air sharing. Proc. of the 4th Int. Conf. on Urban Regeneration and Sustainability, The Sustainable City IV, eds U. Manders, C.A. Brebbia \& E. Tiezzi, WIT Press: Southampton, pp. 303-311, 2006.

[5] Wolfram, S., A New Kind of Science, Wolfram Media: Champaign, 2002.

[6] CIA World Factbook, www.cia.gov/cia/publications/factbook/geos/in.html

[7] GeoHive, http://www.xist.org/cntry/.

[8] Philips Group, Creating Value, Sustainability Report 2005, 2006.

[9] Royal Dutch Shell, The Shell Report 2004, 2005. 